Check for updates

Cite this: RSC Adv., 2018, 8, 17202

Received 7th March 2018

Accepted 4th May 2018

DOI: $10.1039 / \mathrm{c} 8 \mathrm{ra02020e}$

rsc.li/rsc-advances

\title{
In situ synthesis of molybdenum carbide/N-doped carbon hybrids as an efficient hydrogen-evolution electrocatalyst $\uparrow$
}

\author{
Jing Li, ${ }^{a}$ Chenmin Zhou, ${ }^{a}$ Jianshuai Mu, ${ }^{a}$ En-Cui Yang ${ }^{* a}$ and Xiao-Jun Zhao (D) *ab
}

\begin{abstract}
The development of non-precious metal based electrocatalysts for the hydrogen evolution reaction (HER) has received more and more attention over recent years owing to energy and environmental issues, and Mo based materials have been explored as a promising candidate. In this work, molybdenum carbide/N-doped carbon hybrids $\left(\mathrm{Mo}_{2} \mathrm{C}(\mathrm{NC})\right.$ were synthesized facilely via one-step high-temperature pyrolysis by adjusting the mass ratio of urea and ammonium molybdate. The $\mathrm{Mo}_{2} \mathrm{C}$ aNC consisted of ultrasmall nanoparticles encapsulated by $\mathrm{N}$-doped carbon, which had high specific surface area. They all exhibited efficient HER activity, and the $\mathrm{Mo}_{2} \mathrm{C}\left(\mathrm{NNC}\right.$ with a mass ratio of $160\left(\mathrm{Mo}_{2} \mathrm{C}(\mathrm{NC}-160)\right.$ showed the best HER activity, with a low overpotential of $90 \mathrm{mV}$ to reach $10 \mathrm{~mA} \mathrm{~cm}{ }^{-2}$ and a small Tafel slope of $50 \mathrm{mV} \mathrm{dec}{ }^{-1}$, which was one of the most active reported $\mathrm{Mo}_{2} \mathrm{C}$-based electrocatalysts. The excellent $\mathrm{HER}$ activity of $\mathrm{Mo}_{2} \mathrm{CaNC}$ 160 was attributed to the following features: (1) the highly dispersed ultrasmall $\mathrm{MO}_{2} \mathrm{C}$ nanoparticles, which exhibited high electrochemically active surface areas; (2) the synergistic effect of the $\mathrm{N}$-doped carbon shell/matrix, which facilitated the electron transport.
\end{abstract}

\section{Introduction}

With the increase of traditional fossil fuel energy consumption and the associated environmental pollution, considerable efforts have been devoted to exploiting sustainable and clean energy sources to solve the intractable energy and environmental problem. Hydrogen, as a key energy carrier, has been regarded as one of the most promising alternatives to traditional fossil fuels. ${ }^{1}$ Electrochemical water splitting driven by green energy resources has been considered as a promising approach to produce hydrogen fuel. ${ }^{2}$ Water splitting requires efficient electrocatalysts to promote the hydrogen evolution reaction (HER) at low overpotentials. It is well known that platinum (Pt) is the most active HER electrocatalyst, ${ }^{3}$ however its high cost and low abundance limit its large-scale application. Therefore, numerous efforts have been made to develop precious metal-free electrocatalysts with high performance and low cost for practical large-scale hydrogen production.,

So far, several non-noble metal-based materials, including transition-metal carbides, ${ }^{6} \quad$ nitrides, $^{7} \quad$ phosphides $^{8}$ and

${ }^{a}$ College of Chemistry, Key Laboratory of Inorganic-Organic Hybrid Functional Material Chemistry, Ministry of Education, Tianjin Key Laboratory of Structure and Performance for Functional Molecules, Tianjin Normal University, Tianjin 300387, P. R. China.E-mail: encui_yang@163.com; xiaojun_zhao15@163.com; Fax:+86-2223766556

${ }^{b}$ Collaborative Innovation Center of Chemical Science and Engineering, Tianjin, 300071, China

† Electronic supplementary information (ESI) available. See DOI: 10.1039/c8ra02020e chalcogenides $^{9}$ have received more and more attention as alternative HER electrocatalysts. Among these catalysts, transition-metal carbides have recently received a great amount of attention because of their similar electronic structure to that of Pt, good corrosion resistance and stability. ${ }^{10}$ Particularly, one such carbide, molybdenum carbide $\left(\mathrm{Mo}_{2} \mathrm{C}\right)$ is one of the most potential transition-metal carbides due to its efficient catalytic activity, good conductivity, high melting point and low cost. ${ }^{\mathbf{1 1 - 1 5}}$ Recently, constructing various $\mathrm{Mo}_{2} \mathrm{C}$ nanomaterials with particular morphology such as nanowires, ${ }^{\mathbf{1 6}}$ nanosheets ${ }^{\mathbf{1 7}}$ and nanotubes ${ }^{\mathbf{1 8}}$ enhanced their HER performance owing to exposure of more active sites. $\mathrm{Mo}_{2} \mathrm{C}$ nanomaterials are generally obtained by the high-temperature pyrolysis of precursors containing molybdenum and carbon/organic compounds. ${ }^{\mathbf{1 9 , 2 0}}$ However the high-temperature pyrolysis may lead to inevitable aggregation and/or excessive growth, which results in low specific surface area and subsequently low density of catalytic active sites. Therefore, it is still challenging to prepare $\mathrm{Mo}_{2} \mathrm{C}$ with well-defined nanostructures and high specific surface area to expose more catalytical active sites for enhancing HER performance. $\mathrm{Mo}_{2} \mathrm{C}$ nanoparticles has been synthesized by the 'urea glass' route with $\mathrm{MoCl}_{5}$ and urea as precursor, but exhibited low specific surface area. ${ }^{19}$ And some works reported that using ammonium molybdate and some organic compounds (for example glucose and dicyanamide) as Mo and carbon sources produced the $\mathrm{Mo}_{2} \mathrm{C}$ nanomaterials with high specific surface area. ${ }^{21,22}$ Therefore, changing the precursor of Mo and carbon sources might a convenient procedure for constructing $\mathrm{Mo}_{2} \mathrm{C}$ nanomaterials with new nanostructures and 
high specific surface area in order to enhance their HER performance.

Herein, we utilized urea and ammonium molybdatetetrahydrate as carbon and Mo sources to prepare $\mathrm{Mo}_{2} \mathrm{C} @ N C$ via onestep procedure by changing the urea/metal ratio. The obtained $\mathrm{Mo}_{2} \mathrm{C} @ \mathrm{NC}$ had high specific surface areas, exhibited excellent electrocatalytic HER activity with a low overpotential of $90 \mathrm{mV}$ to reach $10 \mathrm{~mA} \mathrm{~cm}{ }^{-2}$ and a small Tafel slope of $50 \mathrm{mV} \mathrm{dec}^{-1}$, which was one of the most active reported $\mathrm{Mo}_{2} \mathrm{C}$-based electrocatalysts.

\section{Material and methods}

\section{Materials}

Ammonium molybdatetetrahydrate, urea and potassium hydroxide were purchased from HeownsBiochem Technologies (Alpharetta GA, USA). Nafion solution (5\% in a mixture of lower aliphatic alcohols and water) and Pt/C (20\% Pt on Vulcan XC72) were purchased from Sigma-Aldrich (St. Louis, USA).

\section{Preparation of $\mathrm{Mo}_{2} \mathrm{C} @ \mathrm{NC}$}

Urea and ammonium molybdatetetrahydrate $(20 \mathrm{mg})$ with different mass ratios ( $R$ (urea/ammonium molybdatetetrahydrate) $=80,160,240$ and 320) were dissolved into $15 \mathrm{~mL}$ water, evaporated in a constant temperature bath at $100{ }^{\circ} \mathrm{C}$ under stirring, and then dried into white precursors. The precursors were placed on quartz boats with a cover, and transferred to a quartz tube furnace. They were heated at $400{ }^{\circ} \mathrm{C}$ with a ramp of $2{ }^{\circ} \mathrm{C} \mathrm{min}{ }^{-1}$ in $\mathrm{N}_{2}$ atmosphere, and further $800{ }^{\circ} \mathrm{C} \mathrm{min}{ }^{-1}$ for $6 \mathrm{~h}$ with a ramp of $5{ }^{\circ} \mathrm{C} \mathrm{min}^{-1}$ to obtain black products. The products were named as $\mathrm{Mo}_{2} \mathrm{C} @ \mathrm{NC}-80, \mathrm{Mo}_{2} \mathrm{C} @ \mathrm{NC}-160$, $\mathrm{Mo}_{2} \mathrm{C} @ \mathrm{NC}-240$ and $\mathrm{Mo}_{2} \mathrm{C} @ \mathrm{NC}-320$, respectively.

\section{Materials characterization}

$\mathrm{X}$-ray powder diffraction (XRD) patterns were measured by a D8 ADVANCE X-ray diffractometer (Bruker, Germany) with $\mathrm{Cu} \mathrm{K} \alpha$ radiation. The $\mathrm{C}$ content was measured by vario $\mathrm{EL}$ cube elemental analysis system (Elementar, Germany). The morphologies of products and EDX spectra were performed using a Nova Nano SEM 230 scanning electron microscope (FEI, USA) and a Tecnai G2 F20 transmission electron microscope (FEI, USA). X-ray photoelectron spectroscopy (XPS) was obtained by an AXIS Ultra DLD X-ray photoelectron spectroscopy (Shimadzu, Japan). $\mathrm{N}_{2}$ adsorption-desorption isotherms were measured by an ASAP 2020 Physisorption Analyzer (Micromeritics, USA), and the specific surface areas were calculated by the Brunauer-Emmett-Teller (BET) method.

\section{Electrochemical measurements}

The electrocatalyst was $(4 \mathrm{mg})$ dispersed in ethanol $(0.475 \mathrm{~mL})$ containing $5 \%$ Nafion solution $(25 \mu \mathrm{L})$ under ultrasonic irradiation for $20 \mathrm{~min}$ to obtain a homogeneous ink. Then $8 \mu \mathrm{L}$ ink was transferred onto a glassy carbon electrode (GCE) with $3 \mathrm{~mm}$ diameter and dried at $30{ }^{\circ} \mathrm{C}$. For comparison, the same amount of Pt/C sample was dropped onto the GCE.
Electrochemical experiments were performed by a threeelectrode system with catalysts modified GCE as the working electrode, a graphite rod as the counter electrode and a saturated $\mathrm{Ag} / \mathrm{AgCl}$ as the reference electrode at $25{ }^{\circ} \mathrm{C}$. Potentials were referenced to a reversible hydrogen electrode: $E_{\mathrm{RHE}}(\mathrm{V})=$ $E_{\mathrm{Ag} / \mathrm{AgCl}}+0.198+0.059 \times \mathrm{pH}$. Prior to the experiments, the working electrode was cycled two hundreds times at a scan rate of $100 \mathrm{mV} \mathrm{s}^{-1}$. Linear sweep voltammetry (LSV) were recorded in $1 \mathrm{M} \mathrm{KOH}$ at a scan rate of $5 \mathrm{mV} \mathrm{s}^{-1}$ to obtain the polarization curves. The data were corrected for background current and iR losses. The Turn Over Frequency (TOF) values were calculated using equation: TOF $=j S_{\text {geo }} / 2 F n$, by assuming every metal atom was involved in the catalytic reaction. ${ }^{23}$ Here, $j\left(\mathrm{~mA} \mathrm{~cm}{ }^{-2}\right)$ was the measured current density at $\eta=90 \mathrm{mV}$. $S_{\text {geo }}$ was the surface area of glassy carbon $\left(0.07065 \mathrm{~cm}^{2}\right)$. The number 2 was the number of electrons per mole of $\mathrm{H}_{2} . F$ was Faraday's constant (96 $485.3 \mathrm{C} \mathrm{mol}^{-1}$ ) and $n$ was the moles of the metal atom on the electrode based on the loading mass and molecular weight of the coated catalysts. The electrochemically active surface areas (ECSA) of the electrocatalysts were calculated by the doublelayer capacitor with the reported electrochemical method. ${ }^{21}$ The cyclic voltammograms (CVs) were performed with different rates from 20 to $100 \mathrm{mV} \mathrm{s}^{-1}$ in the range of $0.15-0.25 \mathrm{~V}(v s$. RHE). The electrochemical impedance spectroscopy (EIS) measurements were carried out using an Autolab potentiostat (Eco Chmie, The Netherlands) in the frequency range from 100 $\mathrm{KHz}$ to $0.1 \mathrm{~Hz}$. The EIS data were analyzed and fitted with the ZView software. The solution resistances $(R)$ were measured by EIS, and calculated to be about $8 \Omega$, which was used for the iR correction. The stability was tested at a scan rate of $50 \mathrm{mV} \mathrm{s}^{-1}$ for 2000 cycles and by long-term chronoamperometry.

\section{Results and discussion}

\section{Characterization of $\mathrm{Mo}_{2} \mathrm{C} @ \mathrm{NC}$}

The synthesis of $\mathrm{Mo}_{2} \mathrm{C} @ \mathrm{NC}$ was achieved by simple thermal treatment of the inexpensive starting materials (urea and ammonium molybdatetetrahydrate) in $\mathrm{N}_{2}$ atmosphere. The synthesized products with different mass ratios of urea/ ammonium molybdatetetrahydrate were confirmed by X-ray diffraction. At the mass ratio $R=80, \mathrm{Mo}_{2} \mathrm{C}$ (JCPDS card no. 35-0787) with diffraction peaks of (100), (002), (101), (102), (110), (103) and (112) was obtained (Fig. 1). ${ }^{24}$ No other crystalline phases (for example, molybdenum nitride and $\mathrm{MoO}_{x}$ ) could be

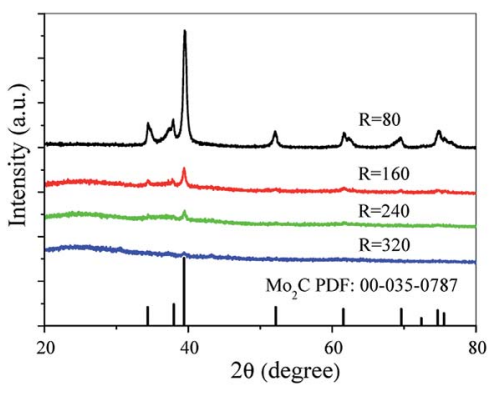

Fig. 1 XRD patterns of different $\mathrm{MO}_{2} \mathrm{C}$ aNC. 
observed in the XRD patterns, indicating its purity. While, with a further increase to $R=160,240$ and 320, the diffraction peaks of the three $\mathrm{Mo}_{2} \mathrm{C}$ products decreased, and an evident broad peak around $26^{\circ}$ corresponding to graphene (002) crystal planes was presented, showing the formation of amorphous carbon and the high content of carbon, compared with $\mathrm{Mo}_{2} \mathrm{C} @ \mathrm{NC}-80 .{ }^{18}$ To better know the elemental composition of $\mathrm{Mo}_{2} \mathrm{C}$ products, EDX analysis was measured. The EDX spectra showed the $\mathrm{Mo}_{2} \mathrm{C}$ products consisted of $\mathrm{C}, \mathrm{Mo}, \mathrm{N}$ and $\mathrm{O}$ elements, and the carbon content increased as the increase of urea amount. (Fig. S1†). The precise free carbon content of the different $\mathrm{Mo}_{2} \mathrm{C}$ products was calculated by the results of elemental analysis system (Table S1†), which verified the above XRD and EDX results. There was no carbon peak for $\mathrm{Mo}_{2} \mathrm{C} @ \mathrm{NC}-80$, possibly due to the relatively low urea used for its synthesis, whereas high amount of urea could lead to poor crystallinity for $\mathrm{Mo}_{2} \mathrm{C} @ \mathrm{NC}-160, \mathrm{Mo}_{2} \mathrm{C} @ \mathrm{NC}-$ 240 and $\mathrm{Mo}_{2} \mathrm{C} @ N C-320$ products. During the first annealing at $400{ }^{\circ} \mathrm{C}$, the pyrolysis of urea could result in $\mathrm{g}-\mathrm{C}_{3} \mathrm{~N}_{4}$ material, which had a stacked 2D lamellar structure similar to graphite. ${ }^{25,26}$ And during the second annealing, the pyrolysis g$\mathrm{C}_{3} \mathrm{~N}_{4}$ and formed molybdenum oxide from the first annealing led to the formation of graphitic carbon, because Mo species could promote the catalytic growth of carbon from the decomposed intermediates of $\mathrm{g}-\mathrm{C}_{3} \mathrm{~N}_{4} \cdot{ }^{21}$ It was concluded that adjusting the mass ratios of urea/ammonium molybdatetetrahydrate would result in the formation of $\mathrm{Mo}_{2} \mathrm{C} @ \mathrm{NC}$ with different crystalline degree and carbon content. The different crystalline degree and carbon content of synthesized $\mathrm{Mo}_{2} \mathrm{C} @ N C$ catalysts might affect their electrochemical HER performance.

The morphology of synthesized products was characterized by SEM and TEM. $\mathrm{Mo}_{2} \mathrm{C} @ \mathrm{NC}-80$ had a mixture of nanoparticles and nanoplates (Fig. S2a and $\mathrm{b} \uparrow$ ). At high amount of carbon precursors, the morphology of $\mathrm{Mo}_{2} \mathrm{C} @ \mathrm{NC}-160, \mathrm{Mo}_{2} \mathrm{C} @ \mathrm{NC}-240$ and $\mathrm{Mo}_{2} \mathrm{C} @ \mathrm{NC}-320$ products exhibited loose and porous nanoflakes (Fig. S2c-h†). TEM images showed that the nanoflakes constructed by ultrasmall nanoparticles with an average size of about $2.3 \mathrm{~nm}$ (Fig. 2a and b). HRTEM images further corroborated that the ultrasmall $\mathrm{Mo}_{2} \mathrm{C}$ nanoparticles embedded within carbon matrix with several layers, although amorphous carbon dominated the carbon matrix around the $\mathrm{Mo}_{2} \mathrm{C}$ nanoparticles (Fig. $2 \mathrm{c}$ and d). The lattice spacing on the $\mathrm{Mo}_{2} \mathrm{C}$ nanoparticles was $0.24 \mathrm{~nm}$, which corresponds to the (002) crystal planes of $\mathrm{Mo}_{2} \mathrm{C}$ phase. The carbon matrix should be resulted from decomposed $\mathrm{g}-\mathrm{C}_{3} \mathrm{~N}_{4}$ via the second annealing, accompanying the reduction of molybdenum oxide and the production of $\mathrm{Mo}_{2} \mathrm{C}$. The elemental mapping (Fig. S3 $\dagger$ ) revealed that the $\mathrm{C}, \mathrm{Mo}$ and $\mathrm{N}$ atoms were homogeneously distributed over the entire material, suggesting that the ultrasmall $\mathrm{Mo}_{2} \mathrm{C}$ nanocrystals were uniformly distributed within the $\mathrm{N}$-doped carbon matrices. The ultrasmall size and uniform distribution of $\mathrm{Mo}_{2} \mathrm{C}$ nanoparticles might be ascribed to the confining effect of $\mathrm{g}-\mathrm{C}_{3} \mathrm{~N}_{4}$ lamellar structure produced from urea during the first annealing.

To confirm the chemical composition and valence states of $\mathrm{Mo}_{2} \mathrm{C} @ N C$, the XPS spectra were studied. The XPS survey spectrum of $\mathrm{Mo}_{2} \mathrm{C} @ \mathrm{NC}-160$ indicated the existence of Mo, C, N and $\mathrm{O}$ elements (Fig. 3a). The Mo 3d XPS spectrum displayed

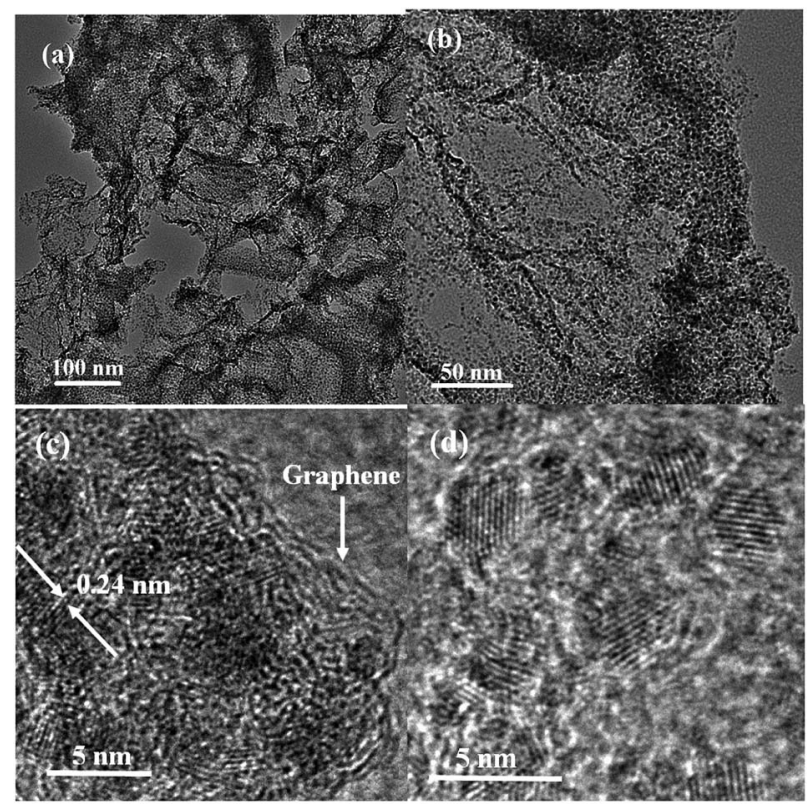

Fig. 2 ( $a$ and b) TEM and (c and d) HRTEM images of $\mathrm{Mo}_{2} \mathrm{C}(\mathrm{NNC}-160$ nanomaterial.

three different oxidation states at 228.8, 229.7 and $232.4 \mathrm{eV}$, which could be ascribed to $\mathrm{Mo} 3 \mathrm{~d}_{5 / 2}$ of $\mathrm{Mo}_{2} \mathrm{C}, \mathrm{MoO}_{2}$ and $\mathrm{MoO}_{3}$, respectively (Fig. 3b). ${ }^{27}$ It has been reported that $\mathrm{Mo}_{2} \mathrm{C}$ was prone to oxidation at the surface when exposed to air. ${ }^{28}$ The $\mathrm{C} 1 \mathrm{~s}$ peaks at 284.6, 285.6 and $289.4 \mathrm{eV}$ could be attributed to the $\mathrm{C}$ atoms of $\mathrm{C}-\mathrm{C} / \mathrm{C}=\mathrm{C}, \mathrm{C}-\mathrm{N}$, and $\mathrm{O}-\mathrm{C}=\mathrm{O}$ species, respectively (Fig. 3c) ${ }^{11,29}$ However, no carbidic peak (ca. $284.2 \mathrm{eV}$ ) was observed. This might be caused by the graphitic carbon on the surface, which covered the signal of the carbidic carbon in a similar region of binding energy. The $\mathrm{N}$ 1s XPS spectrum showed the predominant contribution from pyridinic $\mathrm{N}$ (398.2 $\mathrm{eV})$ and some minor contribution from graphitic $\mathrm{N}(401.1 \mathrm{eV})$ (Fig. 3d). ${ }^{30}$ The peak at $396.4 \mathrm{eV}$ was assigned to the $\mathrm{N} 1 \mathrm{~s}$ signal related to N-Mo bonding. ${ }^{31}$ Therefore, the XPS analysis indicated that the successful incorporation of $\mathrm{N}$ into both the
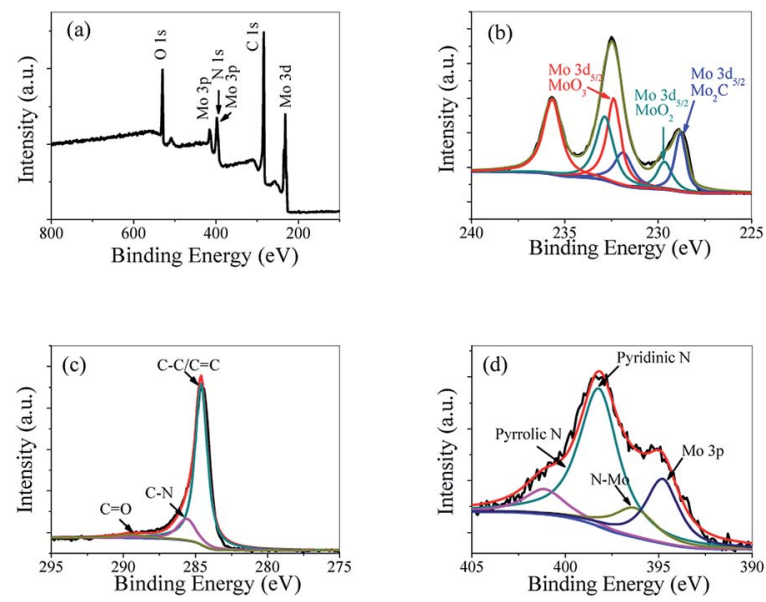

Fig. 3 XPS survey spectra (a), Mo 3d (b), C 1s (c) and N 1s (d) spectra of $\mathrm{Mo}_{2} \mathrm{C} @ \mathrm{NC}-160$ nanomaterial. 
carbon matrix and $\mathrm{Mo}_{2} \mathrm{C}$. Due to the lone electron pair in the plane of the carbon matrix and $\mathrm{Mo}_{2} \mathrm{C}$, these species of doped $\mathrm{N}$ can withdraw electrons and active hydrogen, thus enhance the HER performance of $\mathrm{Mo}_{2} \mathrm{C} @ N C .{ }^{32}$

The specific surface areas and pore size distributions of $\mathrm{Mo}_{2} \mathrm{C} @ \mathrm{NC}$ were determined by $\mathrm{N}_{2}$ adsorption/desorption isotherms. Based on the Brunauer-Emmett-Teller model, the specific surface areas of $\mathrm{Mo}_{2} \mathrm{C} @ N C-80, \mathrm{Mo}_{2} \mathrm{C} @ \mathrm{NC}-160$, $\mathrm{Mo}_{2} \mathrm{C} @ \mathrm{NC}-240$ and $\mathrm{Mo}_{2} \mathrm{C} @ N C-320$ were 70.8, 186.7, 230.9 and $240.2 \mathrm{~m}^{2} \mathrm{~g}^{-1}$, respectively (Fig. S4a and Table $\mathrm{S} 1 \dagger$ ). The specific surface areas were much higher than that of some reported $\mathrm{Mo}_{2} \mathrm{C}$ materials synthesized by other procedures, such as urea glass route $^{\mathbf{1 9}}$ or other carbon sources, ${ }^{21}$ illustrating that employing urea and ammonium molybdate as carbon and Mo precursors could produce the $\mathrm{Mo}_{2} \mathrm{C}$ with high surface area. The high specific surface areas of synthesized $\mathrm{Mo}_{2} \mathrm{C} @ \mathrm{NC}$ nanomaterials might enhance their HER performance. The pore size distributions of $\mathrm{Mo}_{2} \mathrm{C} @ N C$ nanomaterials exhibited a mesopore structure $(2-5 \mathrm{~nm}$, Fig. $\mathrm{S} 4 \mathrm{~b} \dagger)$. The large surface area of $\mathrm{Mo}_{2} \mathrm{C} @ \mathrm{NC}$ nanomaterials might expose more active sites by increasing contact area between the catalysts and electrolyte, and their porosity structures could facilitate transfer of reactants and products, which enhanced mass transport and thus might increase their HER efficiency.

\section{HER catalytic performance of $\mathrm{Mo}_{2} \mathrm{C} @ \mathrm{NC}$}

The electrocatalytic performance of synthesized products for HER were studied in alkaline solution ( $1 \mathrm{M} \mathrm{KOH})$ using a typical three-electrode system. For comparison, the HER performance of $\mathrm{Pt} / \mathrm{C}(20 \mathrm{wt} \%)$ was also evaluated. The polarization curves recorded for each individual electrode were showed in Fig. 4a. The HER activity of $\mathrm{Mo}_{2} \mathrm{C} @ \mathrm{NC}$ followed the order: $\mathrm{Mo}_{2} \mathrm{C} @ \mathrm{NC}-$ $160>\mathrm{Mo}_{2} \mathrm{C} @ N C-80>\mathrm{Mo}_{2} \mathrm{C} @ N C-240>\mathrm{Mo}_{2} \mathrm{C} @ N C-320$, and their HER performances were summarized in Table S1. $\dagger$ $\mathrm{Mo}_{2} \mathrm{C} @ \mathrm{NC}-160$ exhibited excellent catalytic activity with a low overpotential of only $90 \mathrm{mV}$ to reach a current density of $10 \mathrm{~mA}$ $\mathrm{cm}^{2}$, which was 34, 38 and $57 \mathrm{mV}$ lower than those of $\mathrm{Mo}_{2} \mathrm{C} @ \mathrm{NC}-80, \mathrm{Mo}_{2} \mathrm{C} @ \mathrm{NC}-240$ and $\mathrm{Mo}_{2} \mathrm{C} @ \mathrm{NC}-320$. To our best knowledge, the HER activity of $\mathrm{Mo}_{2} \mathrm{C} @ \mathrm{NC}-160$ was superior to most reported Mo-based electrocatalysts (Table 1).

To further investigate the HER reaction mechanism, the Tafel curves were fitted using the equation $\eta=a+b \log |j|$, where $a$ was the intercept, $b$ was the Tafel slope and $j$ was the current density (Fig. 4b). The Tafel slopes of $\mathrm{Mo}_{2} \mathrm{C} @ N C-80$ was calculated to be only $45 \mathrm{mV} \mathrm{dec}{ }^{-1}$, which was lower than those
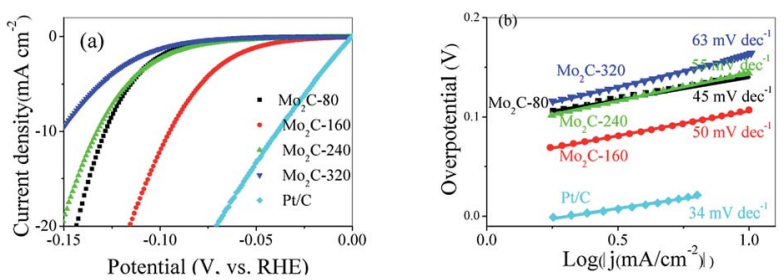

Fig. 4 (a) Polarization curves and (b) Tafel plots of different $\mathrm{Mo}_{2} \mathrm{C} @ \mathrm{NC}$ electrocatalysts. of $\mathrm{Mo}_{2} \mathrm{C} @ \mathrm{NC}-160$ (50 mV dec $\left.{ }^{-1}\right), \mathrm{Mo}_{2} \mathrm{C} @ \mathrm{NC}-240$ (55 mV dec $\left.{ }^{-1}\right)$, $\mathrm{Mo}_{2} \mathrm{C} @ \mathrm{NC}-320$ (63 mV dec ${ }^{-1}$ ), and most of reported $\mathrm{Mo}_{2} \mathrm{C}$ based electrocatalysts. It is well know that hydrogen evolution reaction involves two mechanistic pathways in alkaline condition as follows, which can be interpreted from the Tafel slopes. ${ }^{33,34}$

$$
\text { Step I: } \mathrm{H}_{2} \mathrm{O}+\mathrm{e}^{-}+\text {cat } \rightarrow \underset{\text { (adsorption) }}{\mathrm{H}^{*}-\text { cat }+\mathrm{OH}^{-} \text {Volmer reaction }}
$$
Step II: $2 \mathrm{H}^{*}-$ cat $\rightarrow \uparrow \mathrm{H}_{2}+2$ cat Tafel reaction (chemical desorption)

Step III: $\mathrm{H}^{*}-$ cat $+\mathrm{H}_{2} \mathrm{O}+\mathrm{e}^{-} \rightarrow \uparrow \mathrm{H}_{2}+$ cat $+\mathrm{OH}^{-}$

Heyrovsky reaction

(electrochemical desorption)

The first pathway involves step I and step II called VolmerTafel mechanism, and the second one involves step I and step III known as Volmer-Heyrovsky mechanism. In the VolmerTafel mechanism, if the Volmer reaction (adsorption of $\mathrm{H}^{*}$ on the catalyst surface) is the rate-determining step, the Tafel slope should be $120 \mathrm{mV} \mathrm{dec}{ }^{-1}$, while Tafel slope of $30 \mathrm{mV} \mathrm{dec}-1$ implies Tafel reaction (chemical desorption) is the ratedetermining step. However, in the Volmer-Heyrovsky mechanism, if the Heyrovsky reaction (electrochemical desorption) is the rate determining step, the Tafel slope should be around $40 \mathrm{mV} \mathrm{dec}^{-1}$. The Tafel slopes of $\mathrm{Mo}_{2} \mathrm{C} @ \mathrm{NC}$ ranged from 45 to $63 \mathrm{mV} \mathrm{dec}{ }^{-1}$, indicating that the hydrogen evolution followed the Volmer-Heyrovsky mechanism, and Heyrovsky reaction (electrochemical desorption) was the rate-limiting step. As another important kinetic parameter for HER, the exchange current density $\left(j_{0}\right)$ represented the intrinsic activity of electrocatalysts. Based on the Tafel analysis, the $j_{0}$ of $\mathrm{Mo}_{2} \mathrm{C} @ \mathrm{NC}-160$ was determined to be $7.65 \times 10^{-2} \mathrm{~mA} \mathrm{~cm}^{-2}$, which was much higher than those of $\mathrm{Mo}_{2} \mathrm{C} @ \mathrm{NC}-80\left(0.814 \times 10^{-2} \mathrm{~mA} \mathrm{~cm}{ }^{-2}\right)$, $\mathrm{Mo}_{2} \mathrm{C} @ \mathrm{NC}-240\left(2.42 \times 10^{-2} \mathrm{~mA} \mathrm{~cm}{ }^{-2}\right)$ and $\mathrm{Mo}_{2} \mathrm{C} @ N C-320$ $\left(2.74 \times 10^{-2} \mathrm{~mA} \mathrm{~cm}^{-2}\right)$, revealing the exceptional $\mathrm{H}_{2}$ evolution efficiency of $\mathrm{Mo}_{2} \mathrm{C} @ \mathrm{NC}-160$. In addition, the intrinsic catalytic activity of different $\mathrm{Mo}_{2} \mathrm{C} @ \mathrm{NC}$ electrocatalysts was also studied by the turnover frequency (TOF) for each active site to further accurately assess their HER activity, in which $\mathrm{Mo}_{2} \mathrm{C} @ \mathrm{NC}-160$ showed the highest value of $11.7 \times 10^{-3} \mathrm{~s}^{-1}$, much larger than that of $\mathrm{Mo}_{2} \mathrm{C} @ N C-80\left(0.806 \times 10^{-3} \mathrm{~s}^{-1}\right), \mathrm{Mo}_{2} \mathrm{C} @ N C-240$ $\left(1.16 \times 10^{-3} \mathrm{~s}^{-1}\right)$ and $\mathrm{Mo}_{2} \mathrm{C} @ N C-320\left(0.555 \times 10^{-3} \mathrm{~s}^{-1}\right)$ (Table S1 $\dagger$ ). The low $\eta_{10}$, high $j_{0}$ and high TOF value demonstrated that $\mathrm{Mo}_{2} \mathrm{C} @ \mathrm{NC}-160$ exhibited the best HER performance.

To further investigate the HER kinetics of $\mathrm{Mo}_{2} \mathrm{C} @ \mathrm{NC}$, electrochemical impedance studies were carried out at various overpotentials. The Nyquist and corresponding Bode plots of four $\mathrm{Mo}_{2} \mathrm{C} @ \mathrm{NC}$ electrocatalysts at overpotentials from 0 to $150 \mathrm{mV}$ were obtained (Fig. S6, $\uparrow 5$ and 6). The Nyquist plots exhibited classical one-time constant behavior, and thus a simple electrical equivalent circuit was used to fit the experimental data, where $R_{\mathrm{S}}$ represents the resistance of the medium, 
Table 1 Summary of Mo-based electrocatalysts for HER

\begin{tabular}{|c|c|c|c|c|}
\hline Catalyst & $\begin{array}{l}\text { Catalyst amount } \\
\left(\mathrm{mg} \mathrm{cm}^{-2}\right)\end{array}$ & $\begin{array}{l}\eta_{10} \\
(\mathrm{mV})\end{array}$ & $\begin{array}{l}\text { Tafel slope } \\
\left(\mathrm{mV} \mathrm{dec}^{-1}\right)\end{array}$ & Ref. \\
\hline $\mathrm{Mo}_{2} \mathrm{C} @ \mathrm{NC}-160$ & 0.90 & 90 & 50 & This work \\
\hline $\mathrm{Mo}_{2} \mathrm{C} @ 2 \mathrm{D}-\mathrm{NPCs}$ & 0.73 & 45 & 46 & 11 \\
\hline$m-\mathrm{Mo}_{2} \mathrm{C} / \mathrm{G}$ & 0.269 & 128 & 56 & 36 \\
\hline $\mathrm{Mo}_{2} \mathrm{C} / \mathrm{NCF}$ & 0.28 & 100 & 55 & 37 \\
\hline $\mathrm{Mo}_{x} \mathrm{C}-\mathrm{Ni} @ \mathrm{NCV}$ & 1.1 & 126 & 93 & 30 \\
\hline $\mathrm{MoC}_{x}$ nano-octahedrons & 0.8 & 151 & 59 & 39 \\
\hline$\beta-\mathrm{Mo}_{2} \mathrm{C}$ nanotubes & 0.75 & 112 & 55 & 18 \\
\hline
\end{tabular}

$R_{\text {ct }}$ represents the charge transfer resistance between electrocatalysts and electrolyte, and CPE represents constant phase elements (Fig. 5). ${ }^{29}$ With the increase of overpotentials, the semicircle in the Nyquist plots decreased gradually, which indicated lower charge transfer resistance and better electron transfer ability at higher overpotentials. At $150 \mathrm{mV}$ overpotential, the $R_{\mathrm{ct}}$ value of $\mathrm{Mo}_{2} \mathrm{C} @ \mathrm{NC}-160$ was calculated to be $28.5 \mathrm{Ohm}$, which was smaller than those of $\mathrm{Mo}_{2} \mathrm{C} @ \mathrm{NC}-80$ (45.4 $\mathrm{Ohm}), \mathrm{Mo}_{2} \mathrm{C} @ \mathrm{NC}-240$ (71.6 Ohm) and $\mathrm{Mo}_{2} \mathrm{C} @ \mathrm{NC}-320$ (90.1 $\mathrm{Ohm})$. This indicated $\mathrm{Mo}_{2} \mathrm{C} @ \mathrm{NC}-160$ had the best electron transfer ability. From the Bode plots, only one semicircle at low frequencies has been observed, which was related to the kinetics of the electrochemical HER (Fig. 6). In the Bode phase diagram, the semicircles exhibited potential dependency, and at higher applied potential the phase angle became lower and shifted towards higher frequencies (Fig. 6), which indicated lower resistance and faster reaction kinetics. The comparison of Bode plots for four $\mathrm{Mo}_{2} \mathrm{C} @ \mathrm{NC}$ electrocatalysts at $150 \mathrm{mV}$ overpotential further demonstrated that $\mathrm{Mo}_{2} \mathrm{C} @ \mathrm{NC}-160$ had excellent electron transfer ability and exhibited superior HER activity (Fig. S7 †).

The efficient HER activity of $\mathrm{Mo}_{2} \mathrm{C} @ \mathrm{NC}-160$ electrocatalyst was attributed to its high electron transfer ability as evidenced by the above EIS results. To further investigate the reason why $\mathrm{Mo}_{2} \mathrm{C} @ \mathrm{NC}-160$ electrocatalyst exhibited higher HER activity than the other three $\mathrm{Mo}_{2} \mathrm{C} @ \mathrm{NC}$ electrocatalysts, their electrochemically active surface areas (ECSA) were estimated from the electrochemical double-layer capacitance $\left(C_{\mathrm{dl}}\right)$ of the catalytic surface, which was proportional to their effective electrode

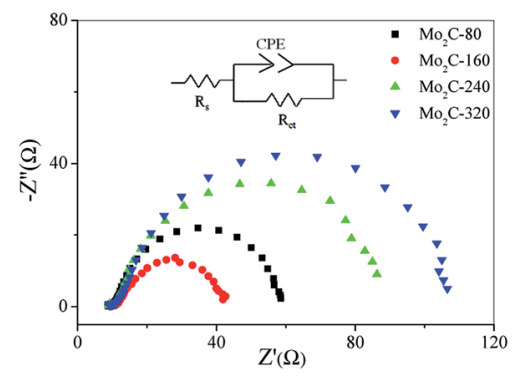

Fig. 5 Comparison of Nyquist plots for different $\mathrm{Mo}_{2} \mathrm{C}$ aNC electrocatalysts at $\eta=150 \mathrm{mV}$. The insert showed the equivalent circuit. surface area. ${ }^{40}$ Therefore, the electrochemical surface areas of different $\mathrm{Mo}_{2} \mathrm{C} @ \mathrm{NC}$ could be compared with one another based on their $C_{\mathrm{dl}}$ values. The $C_{\mathrm{dl}}$ value could be determined by measuring the non-faradaic capacitive current associated with double-layer charging from the scan-rate dependence of cyclic voltammograms (CVs). All measured current in the nonfaradaic potential region was assumed to be due to doublelayer charging, and was equal to the product of the scan rate $(v)$ and the electrochemical double-layer capacitance $\left(C_{\mathrm{dl}}\right)$, as given by eqn 1 .

$$
i_{\mathrm{c}}=v C_{\mathrm{dl}}
$$

Thus, a plot of $i_{\mathrm{c}}$ as a function of $v$ yields a straight line with a slope equal to $C_{\mathrm{dl}}$. The cyclic voltammetry (CV) of $\mathrm{Mo}_{2} \mathrm{C} @ \mathrm{NC}$ were obtained at different scan rates between 0.15 and $0.25 \mathrm{~V}$ versus a reversible hydrogen electrode (RHE) (Fig. S8 $\dagger$ ). A linear correlation was observed for the $\mathrm{Mo}_{2} \mathrm{C} @ \mathrm{NC}$ electrocatalysts when the current density at $0.2 \mathrm{~V}$ was plotted against the scan rate (Fig. 7). From the slopes, the electrochemical double-layer capacitance of $\mathrm{Mo}_{2} \mathrm{C} @ \mathrm{NC}-160$ was estimated to be $50.4 \mathrm{mF}$ $\mathrm{cm}^{-2}$, bigger than those of $\mathrm{Mo}_{2} \mathrm{C} @ \mathrm{NC}-80\left(32.6 \mathrm{mF} \mathrm{cm}{ }^{-2}\right)$, $\mathrm{Mo}_{2} \mathrm{C} @ \mathrm{NC}-240$ (31.7 mF cm ${ }^{-2}$ ) and $\mathrm{Mo}_{2} \mathrm{C} @ \mathrm{NC}-320$ (18.0 mF $\mathrm{cm}^{-2}$ ), thus indicating $\mathrm{Mo}_{2} \mathrm{C} @ \mathrm{NC}-160$ had a higher electrochemically active surface area than other $\mathrm{Mo}_{2} \mathrm{C} @ \mathrm{NC}$
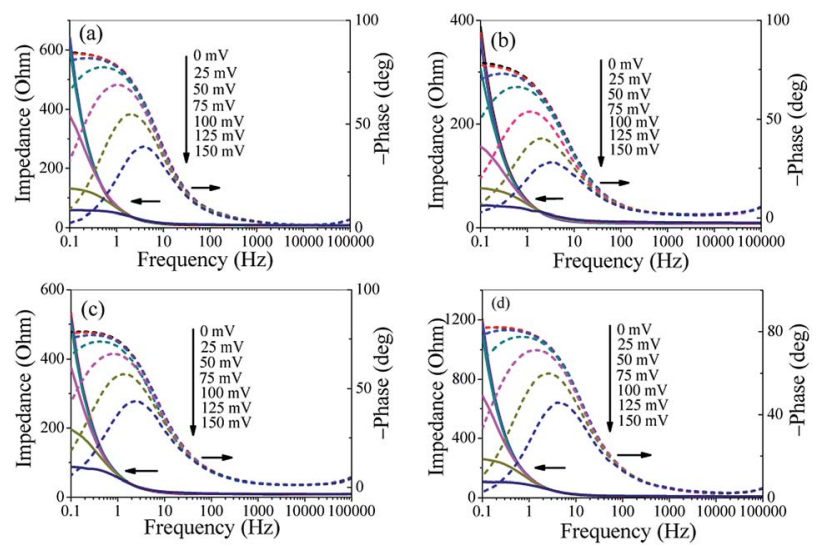

Fig. 6 Bode plots of different $\mathrm{MO}_{2} \mathrm{CaNC}$ electrocatalysts. (a) $\mathrm{Mo}_{2} \mathrm{CaNC}-80$, (b) $\mathrm{Mo}_{2} \mathrm{CaNC}-160$, (c) $\mathrm{Mo}_{2} \mathrm{C}$ aNC-240 and (d) $\mathrm{Mo}_{2} \mathrm{CaNC}-320$. 


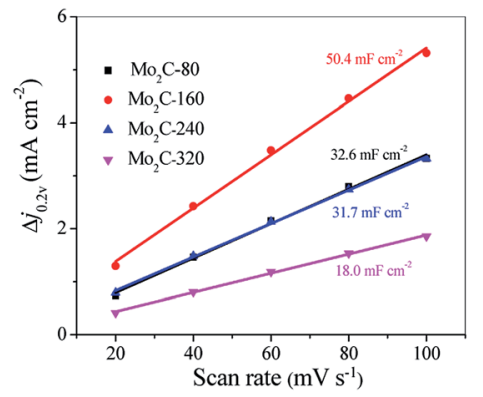

Fig. 7 The differences in current density at $0.2 \mathrm{~V}$ vs. RHE plotted against the scan rate and fitted to a linear regression allows for the estimation of $C_{\mathrm{dl}}$

electrocatalysts. Therefore, the superior HER performance of $\mathrm{Mo}_{2} \mathrm{C} @ \mathrm{NC}-160$ could be associated with its high electrochemically active surface area.

The superior HER performance of $\mathrm{Mo}_{2} \mathrm{C} @ N C-160$ might be mainly attributed to the following factors: on one hand an appropriate amount of $\mathrm{N}$-doped carbon sheets on the $\mathrm{Mo}_{2} \mathrm{C} @ \mathrm{NC}-160$ as supports for uniform distribution of ultrasmall $\mathrm{Mo}_{2} \mathrm{C}$ nanoparticles could improve its conductivity, thus increase the charge transfer ability; on the other hand the high electrochemically active surface areas of $\mathrm{Mo}_{2} \mathrm{C} @ \mathrm{NC}-160$ could expose more catalytic active sites and enhance contact with the electrolyte.

\section{Durability of $\mathrm{Mo}_{2} \mathrm{C} @ \mathrm{NC}-160$ electrocatalyst}

Durability of electrocatalysts for HER was an important issue during the practical application. Therefore, to evaluate the durability of $\mathrm{Mo}_{2} \mathrm{C} @ \mathrm{NC}$ electrocatalyst, cyclic voltammetry sweeps were conducted at a scanning rate of $50 \mathrm{mV} \mathrm{s}^{-1}$ for 2000 cycles in $1 \mathrm{M} \mathrm{KOH}$ media. The $\mathrm{Mo}_{2} \mathrm{C} @ \mathrm{NC}-160$ catalyst after 2000 cycles overlaid almost exactly with the initial one, confirming that the $\mathrm{Mo}_{2} \mathrm{C} @ \mathrm{NC}-160$ catalyst was highly resistant to alkaline media and revealed its excellent electrochemical stability (Fig. 8). The durability of $\mathrm{Mo}_{2} \mathrm{C} @ N C-160$ as HER catalyst was also examined by electrolysis at fixed potentials over extended periods. A small loss in cathodic current density was observed after operation for $12 \mathrm{~h}$ (insert of Fig. 8). The reason of activity loss was that the crystalline phase of $\mathrm{Mo}_{2} \mathrm{C} @ \mathrm{NC}-160$ was destroyed by strongly alkaline solution (Fig. S9†). This exceptional durability of $\mathrm{Mo}_{2} \mathrm{C} @ \mathrm{NC}-160$ demonstrated promise for

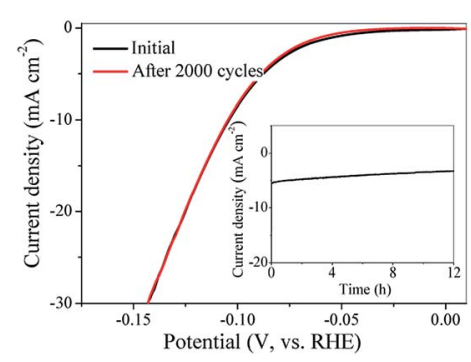

Fig. 8 Stability of the $\mathrm{Mo}_{2} \mathrm{C}$ aNC-160 electrocatalyst with an initial LSV polarization curve and after 2000 cycles. The insert showed the time dependence of catalytic currents for $\mathrm{Mo}_{2} \mathrm{C}$ (aNC-160 at $80 \mathrm{mV}$ overpotential. practical applications of the catalysts over longer periods. The excellent electrochemical stability of the $\mathrm{Mo}_{2} \mathrm{C} @ \mathrm{NC}-160$ could be ascribed to the protection of $\mathrm{N}$-doped carbon shell/matrix around the ultrasmall $\mathrm{Mo}_{2} \mathrm{C}$ nanoparticles.

\section{Conclusions}

In summary, $\mathrm{Mo}_{2} \mathrm{C} @ \mathrm{NC}$ was easily synthesized via a one-step strategy by adjusting the mass ratios of urea and ammonium molybdatetetrahydrate. The $\mathrm{Mo}_{2} \mathrm{C} @ \mathrm{NC}$ nanomaterials with different $\mathrm{N}$-doped carbon content and crystalline obtained at different ratios all exhibited excellent electrocatalytic HER activity, and $\mathrm{Mo}_{2} \mathrm{C} @ \mathrm{NC}-160$ electrocatalyst showed the best HER activity with a low overpotential of only $90 \mathrm{mV}$ to reach 10 $\mathrm{mA} \mathrm{cm}{ }^{-2}$ and a small Tafel slope of $50 \mathrm{mV} \mathrm{dec}^{-1}$. The superior HER activity of $\mathrm{Mo}_{2} \mathrm{C} @ \mathrm{NC}-160$ was associated with highly dispersed ultrasmall $\mathrm{Mo}_{2} \mathrm{C}$ nanoparticles exhibiting high electrochemically active surface areas, and the synergistic effect of $\mathrm{N}$-doped carbon shell/matrix facilitating the electron transportation.

\section{Conflicts of interest}

There are no conflicts to declare.

\section{Acknowledgements}

The work was supported by National Natural Science Foundation of China (Grants 21571140, 21531005, 21371134 and 21703156), 973 Program (2014CB845601), the Program for Innovative Research Team in University of Tianjin (TD13-5074), Tianjin Universities Program for Development of Science and Technology (2017KJ122), and Doctoral Program Foundation of Tianjin Normal University (52XB1508).

\section{References}

1 X. Zou and Y. Zhang, Chem. Soc. Rev., 2015, 44, 5148-5180. 2 A. Eftekhari, Int. J. Hydrogen Energy, 2017, 42, 11053-11077. 3 J. Wang, F. Xu, H. Jin, Y. Chen and Y. Wang, Adv. Mater., 2017, 29, 1605838-1605872.

4 L. Song, X. Wang, F. Wen, L. Niu, X. Shi and J. Yan, Int. J. Hydrogen Energy, 2016, 41, 18942-18952.

5 M. I. Jamesh, J. Power Sources, 2016, 333, 213-236.

6 D. H. Youn, S. Han, J. Y. Kim, J. Y. Kim, H. Park, S. H. Choi and J. S. Lee, ACS Nano, 2014, 8, 5164-5173.

7 B. Cao, G. M. Veith, J. C. Neuefeind, R. R. Adzic and P. G. Khalifah, J. Am. Chem. Soc., 2013, 135, 19186-19192.

8 P. Xiao, M. A. Sk, L. Thia, X. Ge, R. J. Lim, J.-Y. Wang, K. H. Lim and X. Wang, Energy Environ. Sci., 2014, 7, 26242629.

9 C. Tsai, H. Li, S. Park, J. Park, H. S. Han, J. K. Norskov, X. Zheng and F. Abild-Pedersen, Nat. Commun., 2017, 8, 15113.

10 S. Meyer, A. V. Nikiforov, I. M. Petrushina, K. Koehler, E. Christensen, J. O. Jensen and N. J. Bjerrum, Int. J. Hydrogen Energy, 2015, 40, 2905-2911. 
11 C. Lu, D. C. Tranca, J. Zhang, F. Rodriguez-Hernandez, Y. Su, X. Zhuang, F. Zhang, G. Seifert and X. Feng, ACS Nano, 2017, 4, 3933-3942.

12 Z. Shi, K. Nie, Z.-J. Shao, B. Gao, H. Lin, H. Zhang, B. Liu, Y. Wang, Y. Zhang, X. Sun, X.-M. Cao, P. Hu, Q. Gao and Y. Tang, Energy Environ. Sci., 2017, 10, 1262-1271.

13 Z. Shi, Y. Wang, H. Lin, H. Zhang, M. Shen, S. Xie, Y. Zhang, Q. Gao and Y. Tang, J. Mater. Chem. A, 2016, 4, 6006-6013.

14 Z. Shi, B. Gao, Q. Mo, Z. J. Shao, K. Nie, B. Liu, H. Zhang, Y. Wang, Y. Zhang, Q. Gao, X. Sun, X. M. Cao, P. Hu and Y. Tang, ChemNanoMat, 2018, 4, 194-202.

15 Y. Wang, Z. Shi, Q. Mo, B. Gao, B. Liu, L. Wang, Y. Zhang, Q. Gao and Y. Tang, ChemElectroChem, 2017, 4, 2169-2177.

16 L. Liao, S. Wang, J. Xiao, X. Bian, Y. Zhang, M. D. Scanlon, X. Hu, Y. Tang, B. Liu and H. H. Girault, Energy Environ. Sci., 2014, 7, 387-392.

17 Y. Pan, Y. Liu, J. Zhao, K. Yang, J. Liang, D. Liu, W. Hu, D. Liu, Y. Liu and C. Liu, J. Mater. Chem. A, 2015, 3, 16561665.

18 F.-X. Ma, H. B. Wu, B. Y. Xia, C.-Y. Xu and X. W. Lou, Angew. Chem., Int. Ed., 2015, 54, 15395-15399.

19 C. Giordano, C. Erpen, W. Yao and M. Antoniett, Nano Lett., 2008, 8, 4659-4663.

20 C. A. Wolden, A. Pickerell, T. Gawai, S. Parks, J. Hensley and J. D. Way, ACS Appl. Mater. Interfaces, 2011, 3, 517-521.

21 R. Ma, Y. Zhou, Y. Chen, P. Li, Q. Liu and J. Wang, Angew. Chem., Int. Ed., 2015, 54, 14723-14727.

22 C. Tang, A. Sun, Y. Xu, Z. Wu and D. Wang, J. Power Sources, 2015, 296, 18-22.

23 J. Song, C. Zhu, B. Z. Xu, S. Fu, M. H. Engelhard, R. Ye, D. Du, S. P. Beckman and Y. Lin, Adv. Energy Mater., 2017, 7, 1601555-1601563.

24 Q.-C. Zhu, S.-M. Xu, M. M. Harris, C. Ma, Y.-S. Liu, X. Wei, H.-S. Xu, Y.-X. Zhou, Y.-C. Cao, K.-X. Wang and J.-S. Chen, Adv. Funct. Mater., 2016, 26, 8514-8520.
25 J. Mu, J. Li, X. Zhao, E.-C. Yang and X.-J. Zhao, RSC Adv., 2016, 6, 35568-35576.

26 Y. Zhang, J. Liu, G. Wu and W. Chen, Nanoscale, 2012, 4, 5300-5303.

27 K. Ojha, S. Saha, H. Kolev, B. Kumar and A. K. Ganguli, Electrochim. Acta, 2016, 193, 268-274.

28 H. Vrubel and X. Hu, Angew. Chem., Int. Ed., 2012, 51, 1270312706.

29 Y. Zhang, Y. Wang, S. Jia, H. Xu, J. Zang, J. Lu and X. Xu, Electrochim. Acta, 2016, 222, 747-754.

30 S. Wang, J. Wang, M. Zhu, X. Bao, B. Xiao, D. Su, H. Li and Y. Wang, J. Am. Chem. Soc., 2015, 137, 15753-15759.

31 Y.-Y. Chen, Y. Zhang, W.-J. Jiang, X. Zhang, Z. Dai, L.-J. Wan and J.-S. Hu, ACS Nano, 2016, 10, 8851-8860.

32 C. Lu, D. Tranca, J. Zhang, F. R. Hernandez, Y. Su, X. Zhuang, F. Zhang, G. Seifert and X. Feng, ACS Nano, 2017, 11, 39333942 .

33 W. Zhou, J. Zhou, Y. Zhou, J. Lu, K. Zhou, L. Yang, Z. Tang, L. Li and S. Chen, Chem. Mater., 2015, 27, 2026-2032.

34 S. Bukola, B. Merzougui, S. E. Creager, M. Qamar, L. R. Pederson and M. N. Noui-Mehidi, Int. J. Hydrogen Energy, 2016, 41, 22899-22912.

35 X. Fan, Y. Liu, Z. Peng, Z. Zhang, H. Zhou, X. Zhang, B. I. Yakobson, W. A. Goddard III, X. Guo, R. H. Hauge and J. M. Tour, ACS Nano, 2017, 11, 384-394.

36 L. Huo, B. Liu, G. Zhang and J. Zhang, ACS Appl. Mater. Interfaces, 2016, 8, 18107-18118.

37 Y. Huang, Q. Gong, X. Song, K. Feng, K. Nie, F. Zhao, Y. Wang, M. Zeng, J. Zhong and Y. Li, ACS Nano, 2016, 10, 11337-11343.

38 H. L. Lin, Z. P. Shi, S. N. He, X. Yu, S. N. Wang, Q. S. Gao and Y. Tang, Chem. Sci., 2016, 7, 3399-3405.

39 H. B. Wu, B. Y. Xia, L. Yu, X.-Y. Yu and X. W. Lou, Nat. Commun., 2015, 6, 6512-6519.

40 Y. Liu, G. Yu, G.-D. Li, Y. Sun, T. Asefa, W. Chen and X. Zou, Angew. Chem., Int. Ed., 2015, 54, 10752-10757. 